\title{
PARTICIPAÇÃO DE ESTUDANTES COM SÍNDROME DE DOWN NAS AULAS DE EDUCAÇÃO FÍSICA
}

\author{
Amanda Machado Teixeira ${ }^{1}$ \\ Mauren Lúcia de Araújo Bergmann² \\ Jaqueline Copetti3
}

\section{RESUMO}

Este estudo tem como objetivo verificar se os estudantes com Síndrome de Down de um município da Fronteira oeste do RS participam das aulas de Educação Física, descrevendo como ocorre esta participação, e de que forma os pais/responsáveis e os professores de Educação Física desses alunos entendem e contribuem para o processo inclusivo dos mesmos, nas aulas de Educação Física escolar. Para tanto, participaram do estudo quatro estudantes com síndrome de Down de duas escolas públicas e uma privada, quatro pais/responsáveis e três professoras de Educação Física. Foram realizadas entrevistas semiestruturadas com todos os participantes do estudo, bem como, empregada observação sistemática das aulas, de forma direta e não participante, para aqueles estudantes que participavam das aulas de Educação Física. Verificou-se que apenas duas estudantes, matriculadas em instituição privada de ensino, frequentam as aulas de Educação Física, mas essa participação não ocorre de forma efetiva. Ainda, identificou-se que a abordagem do professor de Educação Física e a escolha dos conteúdos, contribuem para a não participação do estudante com Síndrome de Down nas aulas de Educação Física escolar. Frente à realidade encontrada, percebe-se que ainda existem muitas barreiras para que a participação de estudantes com Síndrome de Down nas aulas de Educação Física aconteça de forma efetiva.

Palavras-chave: Educação Física escolar. Síndrome de Down. Educação Inclusiva.

\section{PARTICIPATION OF STUDENTS WITH DOWN SYNDROME IN PHYSICAL EDUCATION CLASSES}

\section{ABSTRACT}

This study aimed to verify if students with Down Syndrome of the municipality of

1 Mestranda do PPG Educação em Ciências: Química da Vida e Saúde da Universidade Federal do Pampa, Uruguaiana, Rio Grande do Sul, Brasil. Orcid iD: http://orcid.org/00000003-1755-3739. E-mail: amandateixeira.m@gmail.com

2 Professora Assistente do Curso de Licenciatura em Educação Física da Universidade Federal do Pampa, Uruguaiana, Rio Grande do Sul, Brasil. Orcid iD: http://orcid.org/00000002-8266-0744. E-mail: moliaraujo@gmail.com

3 Professora Adjunta do Curso de Licenciatura em Educação Física da Universidade Federal do Pampa, Uruguaiana, Rio Grande do Sul, Brasil. Orcid iD: http://orcid.org/0000-0003-48381810. E-mail: jaquecopetti@yahoo.com.br

Revista Exitus, Santarém/PA, Vol. 9, № 4, p. 319 - 346, Out/Dez 2019. 
Uruguaiana/RS participate in Physical Education classes, describing how participation occurs and how the parents/guardians and Physical Education teachers of these students understand the process inclusion criteria. Four students with Down syndrome from two public and one private schools, four parents/guardians and three Physical Education teachers participated in the study. Semi-structured interviews were conducted with all participants of the study, as well as systematic observation of the classes, directly and non-participant, for those students who participated in the Physical Education classes. It was verified that only two students, enrolled in a private educational institution, attend Physical Education classes, but this participation does not occur in an effective way. Also, it was identified that the approach of the Physical Education teacher and the choice of contents, contribute to the non-participation of the student with Down Syndrome in the classes of Physical Education. Faced with the reality found, it is noticed that there are still many barriers to inclusion of students with Down Syndrome in Physical Education classes.

Keywords: Physical Education in School. Down Syndrome. Inclusive Education.

\section{PARTICIPACIÓN DE ESTUDIANTES CON SÍNDROME DE DOWN EN LAS CLASES DE EDUCACIÓN FÍSICA}

\section{RESUMEN}

Este estudio tiene como objetivo verificar si los estudiantes con Síndrome de Down del municipio de Uruguaiana/RS participan en las clases de Educación Física, describiendo cómo ocurre la participación y de qué forma los padres/responsables y los profesores de Educación Física de esos alumnos entienden el proceso de inclusión de los mismos. Para ello, participaron del estudio cuatro estudiantes con síndrome de Down de dos escuelas públicas y una privada, cuatro padres/responsables y tres profesoras de Educación Física. Se realizaron entrevistas semiestructuradas con todos los participantes del estudio, así como fue empleada la observación sistemática de las clases, de forma directa y no participante, para aquellos estudiantes que participaban en las clases de Educación Física. Se verificó que sólo dos estudiantes, matriculados en institución privada de enseñanza, frecuentan las clases de Educación Física, pero esa participación no ocurre de forma efectiva. Se identificó que el abordaje del profesor de Educación Física y la elección de los contenidos, contribuyen a la no participación del estudiante con Síndrome de Down en las clases de Educación Física. Frente a la realidad encontrada, se percibe que todavía existen muchas barreras para la inclusión de estudiantes con Síndrome de Down en las clases de Educación Física.

Palabras clave: Educación Física escolar. Sindrome de Down. Educación Inclusiva.

\section{INTRODUÇÃO}

Na última década, são incontestáveis os avanços relacionados à Educação Especial no Brasil e no mundo. No país, as mudanças iniciaram a partir da Constituição Federal de 1988, que no seu artigo 5, proclama 0 direito à igualdade. Uma década depois, em 1994, na Espanha, foi 
apresentada a Declaração de Salamanca durante a Conferência Mundial sobre Necessidades Educativas Especiais, que reforçou movimentos em favor de uma educação inclusiva no que concerne aos princípios, práticas e políticas relativas às necessidades especiais, e também serviu de guia para a implantação e direcionamento das práticas inclusivas na escola no mundo todo (BRASIL, 1994; COSTA, 2009; LEONARDO; BRAY; ROSSATO, 2009; ALVES; DUARTE, 2012; LUIZ; NASCIMENTO, 2012).

Apesar disso, a sistematização da inclusão social no campo da educação formal, só passou a ser concretizada no Brasil a partir da Lei de Diretrizes e Bases da Educação Nacional (LDBEN) n 9.394/1996, que reconhece a Educação Especial como modalidade de ensino que permeia todos os níveis escolares (BRASIL, 1996). Já no que diz respeito à Educação Física (EF) escolar, o princípio da inclusão foi apresentado somente em 1998, pelo Ministério da Educação por meio dos Parâmetros Curriculares Nacionais, o qual aborda e tem como meta, oportunizar uma aula que contemple a todos os estudantes, buscando reverter o quadro construído historicamente de diferenciação e seleção por características de desempenho e eficiência (BRASIL, 1998).

Em razão disso, de acordo com os dados do Censo Escolar/MEC/INEP, no país o número total de matrículas de alunos com deficiência em classes comuns de ensino regular passou de 43,9 mil em 1998, para 484,3 mil no ano de 2010 (acréscimo de mil por cento). No entanto, mesmo que as políticas de educação inclusiva existam enquanto leis e, a inclusão de estudantes com deficiência esteja acontecendo nas escolas de educação básica, alguns autores criticam a qualidade do ensino e a falta de profissionais capacitados e preparados para atender esses alunos, e defendem que a garantia do direito de acesso à escola regular, está distante da oferta de um ensino adequado e de qualidade, que assegure a permanência do aluno e traga benefícios efetivos à sua aprendizagem (AGUIAR; DUARTE, 2005; LEONARDO; BRAY; ROSSATO, 2009; ALVES; DUARTE, 2012).

Nesse contexto, se tratando das aulas de EF, a inclusão exige um olhar ainda mais amplo e humano do que o tradicional olhar biológico que 
historicamente marca as práticas docentes deste componente curricular (BARBIERI; PORELLI; MELLO, 2008; DARIDO, 2012). A EF ultrapassa a ideia de uma aula voltada para o ensino dos esportes e do gesto motor correto, resultando em uma prática que não acolhe as diferenças (DARIDO; SEABRA, 2012). Além disso, cabe ao professor de EF, estimular a participação efetiva de todos os estudantes nas aulas, dando-as sentido e significado através das diferentes manifestações da cultura corporal de movimento (DARIDO, 2012). Uma vez que, para o estudante com deficiência, a capacidade de realizar as atividades de aula da mesma forma que os colegas, estimulam o seu desenvolvimento em diversos aspectos, não só nas relações de amizade, mas também, instigam sentimentos de autonomia e independência, auxiliando na melhora da qualidade de vida desses indivíduos (ALVES; DUARTE, 2014; FIORINI; MANZINI, 2014; NACIF et al., 2016).

Dentre os diferentes tipos de deficiência existentes e presentes nas escolas de ensino regular, neste estudo, destacamos a Síndrome de Down (SD) que é considerada a principal e mais antiga causa genética de Deficiência Intelectual (PUESCHEL, 2007). As pessoas com SD possuem características morfofuncionais semelhantes, tais como: hipotonia, perfil facial mais achatado, menor tamanho do nariz e cavidades nasais mais estreitas; pálpebras estreitas, levemente oblíquas e dobra palpebral nos cantos internos dos olhos; orelhas e boca pequenas; protusão da língua; dentes pequenos; pescoço curto com diâmetro maior; mãos e pés pequenos e grossos; pés chatos devido à frouxidão ligamentar; braços e pernas mais curtos, baixa estatura e uma tendência à obesidade (PUESCHEL, 1995; SCHWARTZMAN, 2003). Nesse sentido, Omote (1990) destaca as características físicas dos indivíduos com SD como determinantes e que podem influenciar estereótipos e preconceitos, pois facilitam a identificação do sujeito como "deficiente" ou "diferente".

Desse modo, segundo Silva (1996), para as pessoas com SD, a EF se torna ainda mais essencial, pois traz benefícios que fortalecem e enriquecem o desenvolvimento físico, social e mental do indivíduo com a síndrome. Além disso, para Ornelas e Souza (2001), características da SD como hipotonia 
muscular, frouxidão ligamentar, instabilidade atlanto-axial, e dificuldades na coordenação geral e motricidade fina, necessitam de estímulo essencial que possibilite as condições necessárias para o desenvolvimento pleno das capacidades do sujeito com SD. Segundo os autores, as aulas de EF contribuem em todos os aspectos, se o profissional for capacitado e preparado para atender as especificidades desses estudantes (ORNELAS; SOUZA, 2001). No entanto, existem algumas barreiras para a participação efetiva dos estudantes com deficiências nas aulas de EF, como a falta de preparo e capacitação do professor de EF (PADILHA, 2017), a falta de apoio e incentivo de familiares e amigos (JUNG; KALINOSKI; MARQUES, 2017) e, a superproteção dos pais (MARQUES, 2008).

Diante disso, visando contribuir para o melhor entendimento do processo inclusivo de estudantes com SD, de modo a embasar, posteriormente, as discussões, estratégias e ações para superação das barreiras que impedem a participação efetiva desses estudantes nas aulas de EF, este estudo se reveste de importância por seus aspectos fundamentais. Desta forma, a partir de um estudo de caso, esta pesquisa objetivou verificar se os estudantes com SD, de todas as escolas públicas e privadas de um município da Fronteira Oeste do RS, participam das aulas de EF, descrevendo como ocorre esta participação, e de que forma os pais/responsáveis e os professores de EF desses estudantes, entendem e contribuem para o processo inclusivo dos mesmos, nas aulas de EF escolar.

\section{METODOLOGIA}

Este trabalho é um estudo de caso, de natureza qualitativa. O estudo de caso caracteriza-se de uma análise aprofundada de casos particulares, por meio da coleta, análise e interpretação das informações a partir de métodos qualitativos (YIN, 2001). Para Triviños (1987), o estudo de caso é marcado essencialmente, pelo efeito do sujeito no processo e pelos resultados do estudo, exigindo maior severidade na objetivação, originalidade e consistência das ideias. 
Inicialmente, a fim de identificar a relação de estudantes com SD matriculados nas instituições de ensino regular de um município da Fronteira Oeste do RS, foi realizado o contato com todas as escolas que o município dispõe, através das Secretariais Municipal e Regional de Educação e equipe diretiva das escolas particulares. A partir disso, foram identificados, posteriormente ao contato realizado via ligações telefônicas ou visitas nas instituições, 12 estudantes com SD nos anos iniciais do Ensino Fundamental e 04 estudantes com SD nos anos finais do Ensino Fundamental. Como critérios para participação no estudo, o estudante deveria possuir a disciplina de EF na grade curricular do seu nível de ensino, e, ainda, o componente ser ministrado por um professor de EF. Desse modo, a amostra deste estudo está descrita nos quadros 1, 2 e 3, sendo que, a numeração da identificação é correspondente em todas as tabelas, como por exemplo: El, Rl e P1-2. Ou seja, correspondem ao estudante com SD, seu responsável e sua professora de EF, respectivamente.

QUADRO 1 - Descrição dos estudantes com SD participantes do estudo.

\begin{tabular}{|c|c|c|c|c|c|}
\hline Identificação & Sexo & Idade & Série/Ano & $\begin{array}{c}\text { Instituição de } \\
\text { ensino }\end{array}$ & $\begin{array}{c}\text { Participa das } \\
\text { aulas de EF }\end{array}$ \\
\hline E1 & Feminino & 13 & $6^{\circ}$ ano & Privada & Sim \\
\hline E2 & Feminino & 12 & $6^{\circ}$ ano & Privada & Sim \\
\hline E3 & Feminino & 17 & $7^{\circ}$ ano & Pública & Não \\
\hline E4 & Masculino & 21 & $9^{\circ}$ ano & Pública & Não \\
\hline
\end{tabular}

Fonte: As autoras, 2018.

Quadro 2 - Descrição dos pais/responsáveis participantes do estudo.

\begin{tabular}{|c|c|c|c|}
\hline Identificação & Parentesco & Idade & Grau de escolaridade \\
\hline R1 & Mãe & 49 & Ens. Superior Incompleto \\
\hline R2 & Mãe & 44 & Ens. Técnico Superior Completo \\
\hline R3 & Mãe & 38 & Ens. Fundamental Incompleto \\
\hline R4 & Mãe & 59 & Ens. Médio Incompleto \\
\hline
\end{tabular}

Fonte: As autoras, 2018. 
Quadro 3 - Descrição das professoras de EF participantes do estudo.

\begin{tabular}{|c|c|c|c|}
\hline Identificação & Idade & Ano de formação & $\begin{array}{c}\text { Especialização em Educação } \\
\text { Especial e/ou EF Adaptada }\end{array}$ \\
\hline P1-2 & 55 & 1985 & Não \\
\hline P3 & 49 & 1989 & Não \\
\hline P4 & 50 & 1990 & Não \\
\hline
\end{tabular}

Fonte: As autoras, 2018.

Os cuidados éticos deste estudo estão de acordo com as Resoluções $n^{\circ}$ 466/12 de 12 de dezembro de 2012 e no 510, de 07 de abril de 2016 do Conselho Nacional de Saúde. Todos os sujeitos assinaram um Termo de Consentimento Livre e Esclarecido, aceitando participar da pesquisa, bem como, os pais/responsáveis autorizaram seus filhos com SD a participar. Ainda, os estudantes assinaram um Termo de Assentimento Livre e Esclarecido, após a autorização dos responsáveis, também aceitando participar do estudo.

Os participantes, com exceção dos estudantes, preencheram uma ficha de identificação que continha informações como nome, data de nascimento, grau de escolaridade (pais/responsáveis) e ano de formação (professoras). Posteriormente, a coleta dos dados foi realizada por meio de entrevistas semiestruturadas (Quadro 4) com as professoras, pais/responsáveis e alunos com SD, que foram conduzidas em formato de conversa, gravadas, transcritas na íntegra, devolvidas aos sujeitos e analisadas com base na análise de conteúdo descrita por Bardin (2011). Ressalta-se que a realização das entrevistas foi precedida por um estudo piloto, a fim de avaliar e ajustar os instrumentos de coleta. As entrevistas foram realizadas no ambiente escolar ou no domicílio dos estudantes, em um único encontro, com duração média de 10 minutos.

QUADRO 4 - Questões norteadoras da entrevista semiestruturada.

\section{PROFESSORES DE EF}

1. Possui pós-graduação?

2. Já teve ou têm outros alunos com Síndrome de Down? 
3. Possui conhecimentos sobre Educação Especial e/ou Educação Física Adaptada para alunos com Síndrome de Down?

4. Caso possua, onde obteve essas informações (curso de graduação, cursos de extensão, palestras, curso de especialização, mestrado, doutorado, leituras independentes, outros)?

5. O aluno(a) participa das aulas de Educação Física?

Se sim, como você avalia a participação desse aluno(a) nas aulas?

Se não, por que ele(a) não participa?

6. Para você, o que é inclusão?

7. Qual a sua opinião sobre o processo inclusivo de seu aluno(a)?

\section{PAIS/RESPONSÁVEIS}

1. O seu filho(a) faz parte desta escola há quanto tempo?

2. E nesse tempo, seu filho(a) alguma vez foi trocado de turma?

3. O seu filho(a) participa das aulas de Educação Física?

Se sim, como você avalia a participação de seu filho(a) nas aulas?

Se não, por que ele(a) não participa?

4. Seu filho(a) faz alguma atividade física fora do horário das aulas de Educação Física?

5. Para você, o que é inclusão?

6. Qual a sua opinião sobre o processo inclusivo de seu filho(a)?

\section{ESTUDANTES COM SD}

1. Você gosta de vir para a escola?

Por quê?

Se o aluno PARTICIPAR das aulas:

2. Você gosta das aulas de Educação Física?

Por quê? Qual(is) atividade(s) você mais gosta?

Se o aluno NÃO participar das aulas:

3. Você gostaria de participar das aulas de Educação Física?

Por quê? Qual(is) atividade(s) você gostaria de fazer?

Fonte: As autoras, 2018.

Para os alunos com SD participantes das aulas de EF, também foi empregada a observação sistemática das aulas, de forma direta e não participante, no modelo elaborado por Alves e Duarte (2012), onde o contexto das aulas foi observado a partir de três aspectos: 1) compreensão e a execução das atividades propostas; 2) a relação do aluno com seus pares e com o professor de EF; e 3) sua relação com o ambiente de aula. As observações das aulas de EF foram realizadas durante cinco semanas, sendo dois períodos semanais, com duração de 45 minutos cada. Além da ficha de observação, foi utilizado um diário de campo, com o intuito de registrar 
todas as informações pertinentes que não seriam contempladas no outro instrumento de coleta.

\section{RESULTADOS E DISCUSSÃO}

\section{A família e o processo de inclusão escolar do aluno com SD}

Dentre todos os que contribuem para o desenvolvimento da criança com SD, a família é o principal agente responsável por esse processo (LUIZ; NASCIMENTO, 2012). Logo nos primeiros meses de vida, a criança é encaminhada para instituições especializadas, como as Associações de Pais e Amigos dos Excepcionais (APAEs), no caso dos municípios do Rio Grande do Sul. Nesse sentido, metade das mães entrevistadas (R1 e R4) relataram que durante a realização do trabalho especializado na APAE, foram orientadas a matricular seus filhos na escola regular já na Educação Infantil. Enquanto as mães R2 e R3 expuseram que o primeiro contato das filhas na escola de ensino regular, deu-se no primeiro ano do Ensino Fundamental.

Somente a estudante E2, frequenta a mesma escola regular desde a saída da instituição especializada, e nesse período, acompanha uma mesma turma, estando no $6^{\circ}$ ano do Ensino Fundamental, conforme descrito no Quadro 1. A estudante El, que também frequenta $\circ 6^{\circ}$ ano na mesma escola, mas em turma diferente, segundo o relato da mãe, antes de ingressar na escola atual, a filha frequentou outras instituições de Educação Infantil: "[...] Ela foi na APAE, foi na escola "A" e na "B". Desde 1 ano e meio ela vai nas escolinhas [...]" (R1). Já os estudantes E3 e E4, segundo o relato das mães (R3 e R4), frequentaram, além da APAE, duas escolas regulares antes de ingressarem na escola atual.

Além disso, o trabalho de campo oportunizou a informação de que todos os estudantes foram mantidos na mesma turma, no período em que frequentaram determinada instituição de ensino regular, o que, segundo a literatura, contribui significativamente para a construção de relações sociais entre os pares, favorecendo o processo de inclusão da criança com deficiência no ambiente escolar (BATISTA; ENUMO, 2004; ALVES; DUARTE, 2012). Em contrapartida, experiências negativas nas tentativas de inclusão 
da criança com SD em escolas de ensino regular, podem ocasionar diversos prejuízos para o estudante e para a família, dentre eles, o abandono da escola e até mesmo a procura de ajuda médica devido a danos psicológicos advindos das vivências escolares falhas (SMEHA; OLIVEIRA, 2014). As mães R2 e R3 relataram o bullying como uma barreira encontrada no processo de inclusão escolar das filhas:

"Às vezes acontece com colegas, né? Porque são crianças, e criança é um "bicho" imprevisível [...]". (R2)

"[...] problema com colega ela sempre teve, né e sempre vai ter [...]". (R3)

Durante a entrevista, a mãe R3 relata ainda que a filha sofreu de depressão, e não queria frequentar mais a escola atual em decorrência do bullying sofrido por parte de alguns colegas. Ela conta que, ao procurar ajuda médica na APAE, a mesma foi orientada a retornar a filha para a escola especializada, pois muitos indivíduos com SD de idades semelhantes frequentam o local, pelos mesmos motivos da estudante E3, e até mesmo pelos pais preferirem não matricular seus filhos com SD na escola regular. Nessa perspectiva, Smeha e Oliveira (2014) afirmam que a Deficiência Intelectual, como característica marcante em indivíduos com SD, pode ser um elemento que contribui para a não permanência dos mesmos na rede regular de ensino. Para Batista e Mantoan (2007), a dificuldade em conceituar a deficiência intelectual, em grande parte, é fator desencadeador da discriminação sofrida pelas pessoas com essa deficiência, por ela ainda ser uma interrogação e objeto de investigação de diversas áreas do conhecimento.

Em relação ao atendimento educacional recebido nas escolas, as mães R1 e R2 relataram que na escola atual, da rede privada de ensino, as alunas E1 e E2 sempre foram bem atendidas, dispondo do Atendimento Educacional Especializado (AEE) no turno oposto das demais disciplinas curriculares, e uma auxiliar pedagógica por estudante, que as acompanham desde a entrada na escola até o momento da saída. Segundo a legislação, o AEE tem como função: 
[...] complementar ou suplementar a formação do aluno por meio da disponibilização de serviços, recursos de acessibilidade e estratégias que eliminem as barreiras para sua plena participação na sociedade e desenvolvimento de sua aprendizagem (BRASIL, 2009, p. 01).

No entanto, as responsáveis pelos estudantes E3 e E4 matriculados em escolas regulares da rede pública, afirmaram que seus filhos não recebem, além do $\mathrm{AEE}$, o acompanhamento de algum profissional, fora o docente da turma, para dar suporte aos estudantes com SD nas tarefas dos diferentes componentes curriculares:

"[...] Não tem uma pessoa especialmente para ele, o caso dele. É ele, e a turma. Se acompanhou, acompanhou, né. Ainda mais oitava série, que é troca de períodos, troca de professor. Tanto faz, tanto fez se ele copiou ou não [...]". (R4)

A mãe R3 expôs ainda em entrevista, que o pai da estudante com SD gostaria de trocar a filha de escola, devido à falta de atendimento adequado. Além disso, relatou que permanece na escola durante todo o turno de aula da filha, em decorrência de problemas de relacionamento com colegas de classe:

"[...] Que pelo pai dela, ele tirava ela de lá, queria colocar em outra escola. Aí eu disse que não, que não vou tirar de um colégio que ela conhece, pra um que ela não conhece ninguém. Que pra mim, eu fico das 13 h30 até às 17 h. Fico sempre com ela. E em outro colégio vai ser a mesma coisa. [...] eu fico no corredor. Eu fico lá esperando. Qualquer atrito elas me chamam, que sempre tem né." (R3)

A Lei de Diretrizes e Bases da Educação Nacional (LDB), em seu artigo 58, proclama que "haverá, quando necessário, serviços de apoio especializado, na escola regular, para atender às peculiaridades da clientela de Educação Especial" (BRASIL, 1996). Entretanto, no país não existem leis que indiquem as incumbências do auxiliar, quem define quando é necessário o atendimento, nem mesmo formação mínima para tal.

Ainda, segundo os registros feitos no diário de campo, nas escolas públicas e privadas do município investigado, a função de auxiliar 
pedagógico é realizada por estagiários e profissionais concursados, ambos sem formação para atuação com o público-alvo da Educação Especial, que atuam conforme as instruções recebidas pela equipe pedagógica das instituições de ensino. Ainda, no caso das escolas públicas, a quantidade de auxiliares por escola é definida de acordo com os recursos disponíveis, e por vezes, o estudante com deficiência não recebe esse atendimento, devido à falta desses profissionais.

Por fim, quando perguntado às mães sobre o que é inclusão, todas visualizam como uma oportunidade dos filhos participarem das rotinas escolares, da mesma forma que os colegas, sem discriminação e preconceito:

"Eu acho que seja, participar de todas as atividades, sem limitações, dentro dos limites dela, né. E sempre, como é que vou te explicar, se desenvolvendo, né. Sem diferenças." (R1)

"É eles participarem como uma criança normal, junto com as outras, sem diferença nenhuma." (R2)

"Sim, com certeza. Digo, ela estando com pessoas normais, que a gente diz. Estando junto com os outros." (R3)

"Acho que deveria existir. Não teria que existir tanto preconceito, porque como tem preconceito e como a gente sofre com isso." (R4)

Corroborando com a fala das mães, alguns autores afirmam a necessidade da concretização da inclusão social nas escolas, pois o processo inclusivo consiste não somente em adequar espaços, ou adaptar atividades e materiais para que 0 aluno participe das aulas, mas essencialmente, em proporcionar ao aluno a inclusão na rede social presente no ambiente escolar como um todo (BATISTA; ENUMO, 2004; ALVES; DUARTE, 2012; JUNG et al., 2013; ALVES; DUARTE, 2014; SMEHA; OLIVEIRA, 2014). Nesse sentido, para Mantoan (2004), as políticas nacionais devem reconhecer e valorizar as diferenças, para que haja avanço no desenvolvimento e aperfeiçoamento da educação escolar. 


\section{Formação do professor de EF e o trabalho docente}

Das três professoras de EF entrevistadas, conforme descrito no Quadro 3, nenhuma possui formação complementar em Educação Especial ou EF adaptada, e todas ainda relataram que o pouco conhecimento que possuem, se deu através de leituras independentes. Uma das professoras também relatou que participou de uma palestra oferecida pela secretaria de educação local:

\footnotetext{
"Leituras independentes e palestra a gente teve uma no município, sobre Educação Especial. E aí, a gente procura sempre se adaptar né, dentro do que a gente está vivendo." (P1-2)

"De verdade, eu não possuo. Eu até, assim, é uma coisa que eu me cobro até hoje, de procurar me informar mais. Mas, realmente eu não consegui até hoje me dedicar, procurar um pouco mais de literatura a respeito." (P3)

"Já, já li a respeito. Sempre estou a par desses problemas que podem acontecer. Mas são leituras independentes." (P4)
}

Em alguns estudos, a maioria dos professores relatou não se sentirem preparados para trabalhar com alunos com deficiência, também pelo pouco conhecimento que possuem em relação às especificidades desses estudantes (SILVA, 2003; COSTA, 2009; LEONARDO; BRAY; ROSSATO, 2009), corroboram com a fala das professoras entrevistadas no estudo. Além disso, estudos apontam que há uma divergência tanto na infraestrutura, quanto na capacitação dos professores, no que diz respeito à inclusão de alunos com deficiência no ensino regular, pois à medida que eles são "incluídos", o processo de inclusão se desenvolve conforme os recursos disponíveis, e não conforme a necessidade, como deveria ocorrer (LEONARDO; BRAY; ROSSATO, 2009).

Além disso, destaca-se que no currículo da graduação em EF, a EF adaptada só passou a ser ofertada no país a partir do ano de 1987, por meio da Resolução 03/87 do Conselho Federal de Educação (BRASIL, 1987), incluindo a disciplina de "Educação Física e Esporte Especial". Das três professoras entrevistadas, uma possui formação anterior à inclusão da 
disciplina de EF adaptada no currículo da graduação em EF (P1-2), e as demais foram contempladas com os primeiros anos dessa nova estruturação curricular, conforme descrito no Quadro 3. Diante disso, ressalta-se a importância da formação continuada, pois o currículo das licenciaturas, nas últimas décadas, e ainda atualmente, não capacita o professor para um ensino que acolha as diferenças (BRIANT; OLIVER, 2012; TAVARES; SANTOS; FREITAS, 2016).

Nas entrevistas, todas as docentes relataram já terem trabalhado com estudantes com deficiência em suas aulas. A professora P3 mencionou em sua fala, ter tido alunos surdos, e a professora P4, alunos com deficiência física. Ainda, a professora P4 destacou a diferença do atendimento a estudantes com deficiência física e intelectual:

\footnotetext{
"Sim, sim. Já tive alunos com deficiência física. E a gente sempre trabalhava dentro do possível. Faziam o que eles conseguiam, e não era muito difícil. Só que a deficiência física, na minha opinião, é mais fácil de trabalhar do que a deficiência mental, né." (P4)
}

A professora P1-2 relatou, que além das duas estudantes com SD (El e E2) que atende atualmente na escola privada, já atendeu um aluno com SD na rede municipal de ensino. As demais professoras, afirmaram nunca terem trabalhado com escolares com SD, embora uma delas tenha relatado que em algumas escolas por onde atuou, tinham estudantes com SD matriculados, entretanto, eles nunca participaram das aulas de EF.

Para Marques (2008), nos sujeitos com SD, alguns fatores são considerados determinantes para uma vida sedentária, como o baixo incentivo da família, a discriminação, falta de informação e ainda a prevalência de algumas patologias que são comuns em pessoas com a síndrome (MARQUES, 2008). Ainda, Nahas, Barros e Rosa (1999) destacam que em indivíduos com SD, percebe-se uma preferência por atividades de lazer passivas, como ver televisão, ouvir música e outras, determinando um baixo nível de atividade física dessa população. 
Já no que diz respeito à metodologia utilizada para o atendimento dos alunos com deficiência nas aulas de EF junto à turma, a professora P1-2 relata a dificuldade em atender suas alunas com SD, devido ao número excessivo de estudantes na turma:

\begin{abstract}
"Então, tu tens assim, 35 alunos né, e tu tens um (com deficiência). E daí tu ou atende todos né, e eu, o que eu faço. Atendo, dou uma atenção especial para eles, quando elas se encaixam na aula, ok. Mas tem dias que elas não querem, então o que tu faz? Eu tenho que dar um atendimento especializado para elas no cantinho. Aí eu digo (para os demais alunos da turma): "vocês fiquem aí que eu vou dar uma atenção para as gurias". Então, têm que explicar para eles, que elas precisam de um atendimento diferenciado né, e eles entendem, é bem legal." (P1-2)
\end{abstract}

Atualmente, existem legislações que definem o número de estudantes por turma, como no Rio Grande do Sul, onde o Parecer CEED n 1.400/2002 do Conselho Estadual de Educação, recomenda até 25 alunos no $1^{\circ}$ ano; do $2^{\circ}$ ao $4^{\circ}$ ano até 30 alunos e do $5^{\circ}$ ao $8^{\circ}$ ano até 35 alunos. Já em relação à forma com que as aulas são ministradas, destaca-se na fala da professora, um discurso excludente, pois as aulas não são planejadas visando à participação de todos os estudantes, o que muitas vezes, possibilita um ensino segregado, onde as estudantes com SD participam da aula em um "cantinho", e não com os demais colegas de classe.

O contrário do que destaca a professora P4 em sua fala, que afirmou que em sua pouca experiência com estudantes com deficiência nas aulas de EF, para possibilitar a inclusão de seus alunos, foi necessário motivá-los, fazendo com que eles se sentissem bem na aula, e pertencentes ao grupo:

\footnotetext{
"Procurava fazer atividades que eles pudessem fazer. Atividades onde eles pudessem ter integração com os outros alunos, um trabalho mais em grupo. E assim, aos pouquinhos vendo o limite deles, adaptando eles nas atividades. Mesmo aquelas atividades que eles não pudessem fazer, mas conseguir incluir eles na aula. $E$ assim, até para eles se sentirem bem, eles tem que se sentirem bem na aula. Poder saber que eles podem fazer que nem os outros, e aos pouquinhos eu acho que a motivação, motivar esse aluno. Fazer eles se sentirem parte do grupo. Mostrar que ele é importante tanto quanto o outro que está ali." (P4)
} 
No estudo de Alves e Duarte (2014), onde foi analisada a inclusão nas aulas de EF a partir da percepção dos estudantes com deficiência, foi identificado que o sentimento de sentir-se capaz de realizar as atividades da mesma forma que os colegas, contribuem para o processo positivo de inclusão. Do mesmo modo, a inclusão, ao ser analisada a partir da percepção dos colegas de classe de estudantes com SD, foi identificada que, quanto maior a participação do aluno com SD nas atividades de aula, maiores são as possibilidades de construção de relações sociais, como coleguismo e amizade, entre o estudante com deficiência e seus pares (TEIXEIRA; KUBO, 2008).

A partir das entrevistas, foi identificada a percepção de inclusão das professoras P3 e P4, como semelhantes. Ambas elencam o processo inclusivo nas aulas de EF como uma forma de inserir os estudantes com deficiência nas atividades de aula, fazendo com que os mesmos participem da mesma forma que os colegas, dentro de suas limitações:

"Eu acho que a inclusão é participar, é poder participar. A participação é de todos. Eu acho que é poder participar das atividades, sem discriminação. Poder participar, incluir." (P4)

"Então, como a própria palavra já tá dizendo, é uma maneira de incluir aquele aluno que não tá no mesmo nível dos outros, nas aulas de Educação Física. É fazer uma aula adaptada, de alguma forma que o aluno consiga participar, tendo as deficiências que tem." (P3)

Já a professora P1-2 visualiza a inclusão como um processo difícil de ser concretizado, pois os estudantes com deficiência não conseguem interagir por completo com os colegas de classe, principalmente em atividades de caráter competitivo, devido à rejeição dos colegas sem deficiência, aos considerados "menos habilidosos":

"Olha, é bem difícil né. [...] tu tenta fazer com que essa criança se sinta parte do grupo, mas ao mesmo tempo tu te dá conta que não existe essa inclusão, né. Porque ela não consegue, eu vejo assim, eles não conseguem interagir por completo. Se tu vai fazer uma brincadeira, onde tem uma competitividade [...] eles não querem aquele aluno que eles sabem que vai fazer com que 
eles atrase a competição. Então, assim, eu acho bem complicado a questão da inclusão. [...] O especial precisa conviver com quem se diz normal, que eu acho que todo mundo tem as suas deficiências e tudo. Mas não é fácil, não. A questão da inclusão é bem complicado." (P1-2)

Apenas em uma das escolas participantes do presente estudo, foi relatado pela professora de EF (P4), que é mantido o diálogo entre a mesma e a professora do AEE, a fim de discutir as possibilidades de participação dos estudantes com deficiência nas aulas de EF e delinear estratégias para melhor atender esses estudantes. Em relação ao suporte dado aos professores de EF para o atendimento aos alunos com deficiência, de acordo com o trabalho de campo realizado, identificou-se que, de uma forma geral, embora as políticas inclusivas assegurem a oferta de um ensino adequado e de qualidade a todos os estudantes, pouco ou nenhum subsídio é dado para os profissionais docentes obterem êxito neste processo, principalmente em relação à oferta de capacitação. Além disso, percebese na fala das professoras, que a inclusão não depende única e exclusivamente de capacitação, mas da vontade do professor em fazer com que todos os estudantes, independente de suas diferenças, participem efetivamente das aulas de EF.

\section{Participação dos estudantes com SD nas aulas de EF}

Dos estudantes com SD participantes do estudo, metade (E1 e E2) participa das aulas de EF, sendo que essa participação ocorre desde os primeiros anos escolares, na mesma instituição privada de ensino, e no mesmo turno das demais disciplinas curriculares. Por outro lado, a partir dos relatos das mães, em entrevista, foi identificado que os estudantes E3 e E4 nunca participaram das aulas de EF durante seus anos escolares. Os motivos para a não participação, elencados pelas mães R3 e R4, são distintos. A responsável R3 alega que a filha não participa devido à facilidade que têm para cair e se machucar, enquanto a mãe R4 afirma que o filho não participa por desinteresse: 
"Não, por causa dessa questão que ela cai, ela não tem firmeza, entendeu?" (R3)

"Ele não gosta, ele cansa." (R4)

Quando perguntado aos estudantes com SD, se eles gostariam de participar das aulas de EF, o estudante E4, em entrevista, confirma a fala da mãe, respondendo que não gostaria de participar, enquanto a aluna E3, demonstrou interesse, expondo que gostaria de participar da EF. Contrastando com a fala das mães e dos estudantes, quando questionado aos professores sobre os possíveis motivos da não participação dos alunos com SD nas aulas de EF, ambas as professoras (P3 e P4), elencaram como possível motivo a falta de estímulo da família, o que também é destacado por alguns autores como determinante para a não participação de estudantes com deficiência nas aulas de EF, e em atividades físicas de uma forma geral (MARQUES, 2008; JUNG; KALINOSKI; MARQUES, 2017; PADILHA, 2017).

Ainda, complementando, a mãe R4 relatou que seu filho, por morar perto, se desloca a pé e sozinho para a escola, no turno de aula e no contraturno, para participar das atividades escolares, sala de recursos e banda marcial da escola, e que de fato, não participa das aulas de EF pela falta de interesse, já que têm autonomia para ir e vir da escola. Contudo, a mãe R3, como já relatado anteriormente, acompanha a filha durante toda sua estada dentro da escola, o que pode ser um fator que contribui para a não participação nas aulas de EF, visto que, a EF nesta escola é ofertada no turno oposto das demais disciplinas escolares, dificultando o acesso da mãe até a escola.

De acordo com o estudo de campo realizado, verificou-se que nas escolas privadas e algumas municipais, a EF é oferecida no mesmo turno das demais disciplinas curriculares. Entretanto, nas escolas estaduais e em parte das municipais, a EF é ofertada no turno oposto, o que pode ser visto como uma barreira para a frequência dos estudantes, pois significa outro deslocamento para a escola no mesmo dia. Para Souza Júnior e Darido (2009), um dos fatores determinantes das dispensas das aulas de EF, 
possivelmente, está relacionado à disposição da disciplina fora da grade horária curricular regular. Todavia, sabe-se que o AEE também é realizado no turno oposto às demais disciplinas escolares, o que poderia facilitar a participação do estudante com deficiência nas aulas de EF, se a EF e o AEE fossem organizados no mesmo dia. Fator este, que ressalta ainda mais a necessidade de melhor articulação e interesse por parte da família, como também por parte da instituição de ensino.

Em relação à participação das estudantes El e E2 nas aulas de EF, foi identificado através das observações, que ambas as alunas têm boa relação com 0 ambiente de aula e não necessitam de ajuda para locomoção no espaço escolar. Durante a troca de disciplinas, os alunos se deslocavam sozinhos, da sala de aula até o local onde ocorreram as aulas de EF. Todas as aulas observadas aconteceram em um ginásio poliesportivo, pertencente à instituição particular de ensino. A média de alunos por aula observada foi de 29 na turma da estudante El, enquanto na classe da estudante E2, a média foi de 25 alunos.

Em relação às atividades ministradas pela professora de EF (P1-2), os conteúdos predominantemente observados, ao longo das cinco semanas, foram os jogos e os esportes coletivos (futsal, basquete e vôlei). As aulas eram caracterizadas pelo momento inicial, onde ocorria à divisão dos grupos ou separação das equipes pela docente e, no decorrer da aula, aconteciam vários jogos em sequência. As alunas com SD (E1 e E2), durante - período de observação das aulas de EF, em nenhum momento participaram efetivamente das atividades ofertadas pela professora (P1-2), em conjunto com a turma. A estudante El, em alguns momentos participou da divisão inicial das equipes, mas durante o andamento da atividade não participava efetivamente, devido à competitividade de seus colegas e a falta de ludicidade nas atividades, e consequentemente, parecia perder 0 interesse e deixava de participar. Suas demais participações, em boa parte das vezes, ocorriam auxiliando a professora com o material de aula, ou realizando atividades de arremessar e quicar uma bola de iniciação 
esportiva ou de basquete, juntamente com a professora na lateral da quadra.

Contudo, a não participação nas atividades não foi característico somente da estudante El. Quando o conteúdo era os esportes coletivos, parte da turma participava do jogo, organizado pela professora, e parte realizava atividades nas laterais do ginásio, do modo que quisessem, e alguns ainda, preferiam ficar na arquibancada usufruindo de aparelhos eletrônicos. Para alguns autores, a não diversificação de conteúdos pode ser um fator que afasta os alunos das aulas de EF (CHICATI, 2000; TENÓRIO; SILVA, 2015). Além disso, a falta de intervenção ou mediação pedagógica do professor de EF pode estimular a não participação dos alunos menos habilidosos (CRUZ DE OLIVEIRA, 2010; FORTES, 2012; TENÓRIO; SILVA, 2015).

Nesse sentido, Alves e Duarte (2012) em seu estudo, afirmam que a não participação nas aulas de EF, pode causar efeitos negativos ao estudante, como a percepção de não pertencimento ao grupo. Ainda, em outro estudo realizado em 2014, os autores defendem que a sensação de pertencimento ao grupo, é fundamental para o aluno sentir-se incluído (ALVES; DUARTE, 2014). Entretanto, essa participação deve ser efetiva, e o planejamento do professor de EF deve ser elaborado a fim de facilitar a inserção de todos os estudantes na aula, independente de suas características individuais. Segundo Alves e Fiorini (2018), para eliminar as possíveis barreiras de aprendizagem e participação de todos os estudantes, as aulas de EF devem ser estruturadas e planejadas de acordo com as necessidades de cada aluno, e isso possibilitará a prática conjunta de um currículo único para todos (ALVES; FIORINI, 2018).

Já a participação da estudante E2 nas aulas de EF, durante as observações realizadas, era ainda mais breve. Em nenhum momento a estudante demonstrou interesse em participar das atividades que estavam sendo realizadas, e na maior parte do período de aula, ficava sentada na arquibancada observando os colegas realizarem as atividades propostas pela professora (P1-2). Em outros momentos, estimulada pela auxiliar pedagógica, a aluna E2 realizava atividades de arremessar uma bola de 
iniciação esportiva, no espaço da lateral do ginásio, juntamente com a auxiliar e com as colegas que também não estavam participando da aula de EF. Durante as observações, foi percebida a dependência da estudante E2, em relação à presença da auxiliar pedagógica. Ao contrário da estudante El, que durante as aulas de EF observadas, a auxiliar pedagógica esteve presente sem interferir em nenhum momento, apenas acompanhava a aluna na chegada ao ambiente da aula de EF, e na saída para retornar à sala de aula.

A relação das estudantes E1 e E2, com seus pares e com a professora, também foi identificada como não semelhante. A estudante El demonstrou ter mais interesse pelas aulas de EF, e a partir disso, naturalmente, teve mais interações com seus pares e com a professora. Apenas em um período de aula, a auxiliar da aluna E2, não esteve presente. Nesse dia, a estudante E2 demonstrou mais interações com seus colegas, do que geralmente realizava com a presença da auxiliar. A partir disso, percebe-se que a presença de um acompanhante, a todo o momento com a estudante, pode ser um fator que limitou a construção de relações sociais da aluna com seus colegas de classe. Segundo Lorenz (1999), a função do auxiliar pedagógico, é a de oferecer assistência ao estudante com deficiência, somente quando ele tiver necessidade. A autora afirma que a ajuda deve ser dada somente quando solicitada, para que a criança tenha a oportunidade de trabalhar com outras pessoas, e não desenvolver dependência do profissional auxiliar (LORENZ, 1999).

Embora ambas as alunas (E1 e E2) atendessem aos pedidos e orientações da professora de EF, a aluna E2 demonstrou ter maior confiança e respeito com a auxiliar pedagógica. Já a estudante El, em boa parte dos momentos, procurava a professora de EF para a realização de tarefas e atividades, bem como, para demonstrações de carinho e afeto. A aluna E2, interagiu poucas vezes com a professora de EF durante as aulas. Nas relações sociais entre as alunas com SD e os colegas, foi possivel identificar a partir do estudo de campo, que as interações ocorreram de forma parcial em ambos os casos (E1 e E2). Os contatos, quando realizados, em sua 
maioria, por iniciativa das estudantes com SD ou dos colegas, eram breves. No estudo de Alves e Duarte (2012), ao analisarem a participação de estudantes com SD nas aulas de EF, e no estudo de Fiorini e Manzini (2014), com estudantes com deficiência de forma geral, também foram identificadas interações sociais com os colegas de classe de forma pobre e limitada.

No geral, as observações das aulas de EF das estudantes com SD (El e E2), demonstraram que o processo de inclusão no componente curricular de EF ainda é falho, pois além da falta de participação efetiva nas atividades de aula, as estudantes apresentaram algumas limitações em relação às interações sociais com seus pares. Sabe-se que o atual modelo de ensino da EF, muitas vezes, não contempla a riqueza de possibilidades das diversas manifestações corporais. O docente, ao sair do ambiente acadêmico, se depara com uma gama diversa de possibilidades de atuação em diferentes contextos. Se tratando do ambiente escolar, o professor de EF, em conjunto com os demais professores, tem o papel de possibilitar uma aprendizagem efetiva e de qualidade a todos os estudantes, independente das diferenças (BRASIL, 1998). Para isto, o professor deve elaborar estratégias, dentro de suas possibilidades, e de acordo com os limites de cada estudante, para oportunizar a participação efetiva de todos (RECHINELI, 2008; GORGATTl; ROSE JÚNIOR, 2009; FIORINI; MANZINI, 2016; NACIF et al., 2016).

Desse modo, em relação aos estudantes com deficiência, que possuem especificidades distintas dos demais alunos, o atendimento por parte do professor deve ser ainda mais centrado nas individualidades desses estudantes, para que a aprendizagem dos mesmos seja tão efetiva e significativa, quanto para os demais escolares (FIORINI; MANZINI, 2016). No entanto, para que isto ocorra, o professor deve possuir conhecimentos específicos que sirvam como base para o atendimento adequado dos estudantes com necessidades educacionais especiais (TEIXEIRA; KUBO, 2008; GORGATTI; ROSE JÚNIOR, 2009; FIORINI; MANZINI, 2016). Para Alves e Fiorini (2018), o professor de EF deve identificar as individualidades, capacidades, dificuldades e potencialidades de todos os estudantes, e a partir disso 
realizar adaptação curricular, que é fator central do processo inclusivo na escola.

Por fim, a partir das experiências obtidas através do estudo de campo, e de estudos semelhantes encontrados na literatura, percebe-se que ainda existem muitas barreiras para a participação efetiva de estudantes com SD nas aulas de EF, e essa responsabilidade não é única e exclusiva do professor, mas da comunidade escolar de uma forma geral. Além disso, ressalta-se que, se tratando do processo inclusivo na escola, a maior conquista em relação aos direitos das pessoas com deficiência se deu através de leis e normas, mas não que estas possibilitem de fato a inserção dessas pessoas na sociedade (GORGATTI; JÚNIOR, 2009; LEONARDO; BRAY; ROSSATO, 2009).

\section{CONSIDERAÇÕES FINAIS}

Frente à realidade encontrada, percebe-se que ainda é preciso muitas mudanças para que a participação de estudantes com SD nas aulas de EF aconteça efetivamente. Considerando os resultados apresentados no presente estudo, ressalta-se que a falta de capacitação profissional, no que se refere à abordagem do professor e a adaptação dos conteúdos de acordo com as especificidades dos estudantes, a falta de incentivo da família, que por vezes desconhece a importância das aulas de EF no desenvolvimento dos estudantes com SD, e a falta de articulação entre os setores no ambiente escolar, que não atuam colaborativamente para a inclusão, são fatores que dificultam a participação efetiva dos estudantes com SD nas aulas de EF.

Dessa forma, é importante que se estabeleça um diálogo entre a família do aluno com SD, a escola e o professor de EF, na perspectiva de incluir o estudante de forma significativa nas aulas de EF, e no ambiente escolar como um todo. Assim como, o professor de EF, mesmo não possuindo formação prévia em EF Adaptada, deve buscar subsídios dentro de suas possibilidades, para melhor atender esses estudantes, fazendo com que eles participem efetivamente das aulas da mesma forma que seus pares. A partir 
disso, ressalta-se que, o professor de EF, para garantir a participação efetiva dos estudantes com SD nas aulas, deve levar em conta as suas especificidades, assim como dos demais alunos, de modo a possibilitar uma aprendizagem significativa a todos.

Nessa perspectiva, destaca-se que mais estudos devem ser realizados, com o intuito de avaliar a participação de estudantes com SD nas aulas de EF e dos demais componentes curriculares, de modo a possibilitar a criação de estratégias e ações para a participação efetiva desses estudantes nas aulas, e consequentemente, o sucesso em seu processo de escolarização. Uma vez que, incluir não trata-se somente de garantir o acesso do estudante a escola, mas dar subsídios para que o mesmo permaneça no ambiente educacional e se desenvolva de forma integral, como prevê os documentos norteadores da educação no país.

\section{REFERÊNCIAS}

AGUIAR, J. S.; DUARTE, E. Educação Inclusiva: Um Estudo na Área da

Educação Física. Revista Brasileira de Educação Especial, Marília, Mai.-Ago, v.1 1, n.2, p.223-240, 2005.

ALVES, M. L. T.; DUARTE, E. Os caminhos percorridos pelo processo inclusivo de alunos com deficiência na escola: uma reflexão dos direitos construídos historicamente. Revista Educação Especial, Santa Maria, v. 24, n. 40, p. 207218, maio/ago, 2011.

ALVES, M. L. T.; DUARTE, E. A participação de alunos com síndrome de Down nas aulas de Educação Física Escolar: Um estudo de caso. Revista Movimento, Porto Alegre, v. 18, n. 03, p. 237-256, jul/set, 2012.

ALVES, M. L. T.; DUARTE, E. A percepção dos alunos com deficiência sobre a sua inclusão nas aulas de Educação Física escolar: um estudo de caso.

Revista Brasileira de Educação Física e Esporte, São Paulo, Abr-Jun; 28(2):32938, 2014.

ALVES, M. L. T.; FIORINI, M. L. S. COMO PROMOVER A INCLUSÃO NAS AULAS DE EDUCAÇÃO FÍSICA? A ADAPTAÇÃO COMO CAMINHO. Revista da Sobama, Marília, v.19, n.1, p.03-16, Jan./Jun., 2018.

BARBIERI, A. F.; PORELLI, A. B. G.; MELLO, R. A. Abordagens, Concepções e Perspectivas de Educação Física Quanto à Metodologia de Ensino nos Trabalhos Publicados na Revista Brasileira de Ciências do Esporte (Rbce) em 2009. Motrivivência. № 31, p. 223-240. Dez./2008. 
BARDIN, L. Análise de conteúdo. São Paulo: Edições 70; 2011.

BATISTA, M. W.; ENUMO, S. R. F. Inclusão Escolar e Deficiência Mental: Análise da Interação Social entre Companheiros. Estudos de Psicologia, Natal, v. 9, n. 1, p. 101-111, 2004.

BATISTA, C. A. M.; MANTOAN, M. T. E. Atendimento Educacional Especializado em Deficiência Mental. São Paulo: MEC/SEESP, 2007.

BRASIL. Declaração de Salamanca e Linha de Ação sobre Necessidades Educativas Especiais. Brasília: UNESCO, 1994.

BRASIL. Instituto Nacional de Estudos e Pesquisas Educacionais Anísio Teixeira (Inep). Censo Escolar. Diário Oficial da União. Disponível em:

<http://portal.inep.gov.br/basica-censo>. Acesso em: 4 jul. 2016.

BRASIL. Lei de Diretrizes e Bases da Educação (Lei n. 9394, de 20 de dezembro de 1996). Diário Oficial da União, 23 de dezembro, 1996.

BRASIL. Ministério da Educação e Cultura. Conselho Federal de Educação. Resolução 03, de 1987. Fixa os mínimos de conteúdo e duração a serem observados nos cursos de graduação em Educação Física (Bacharelado e/ou Licenciatura Plena). Diário Oficial da União: República Federativa do Brasil: Brasília, DF, 10 set. 1987.

BRASIL. Parâmetros Curriculares Nacionais - Terceiro e Quarto Ciclos do Ensino Fundamental. Brasília, DF: MEC; SEF, 1998.

BRASIL. Resolução n. ${ }^{4}$, de 2 de outubro de 2009. Institui Diretrizes Operacionais para o Atendimento Educacional Especializado na Educação Básica, modalidade Educação Especial. Brasília, DF: CNE/CEB, 2009.

Disponível em: <http://portal.mec.gov.br/dmdocuments/rceb004_09.pdf>. Acesso em: 18 nov. 2018.

BRIANT, M. E. P.; OLIVER, F. C. Inclusão de crianças com deficiência na escola regular numa região do município de São Paulo: conhecendo estratégias e ações. Rev. Bras. Ed. Esp., Marília, v.18, n.1, p. 141-154, Jan.-Mar., 2012.

CHICATI, Karen Cristina. Motivação nas aulas de educação física no ensino médio. Revista da Educação Física, Maringá, v.11, n. 1, p. 97-105, 2000.

Conselho Estadual de Educação. Parecer $n^{\circ}$ 1.400/2002. Estabelece normas para a oferta do Ensino Fundamental no Sistema Estadual de Ensino do Rio Grande do Sul. Disponível em:

<http://www.ceed.rs.gov.br/conteudo/1248/parecer-n\%C2\%BA-1400-2002>. Acesso em: 18 jan. 2019.

COSTA, Fábio R. B. Formação e Desenvolvimento Profissional em Educação

Física Dilemas e Desafios na Educação Inclusiva. 95f. Dissertação (Mestrado) - Programa de Pós-Graduação em Educação Física. Universidade Federal de Pelotas, 2009. 
CRUZ DE OLIVEIRA, R. Na "periferia" da quadra - Educação Física, cultura e sociabilidade na escola. 201f. Tese (Doutorado em Educação Física). Curso de Educação Física, Departamento de Educação Física, Unicamp, Campinas, 2010.

DARIDO, S. C. Diferentes Concepções Sobre o Papel da Educação Física na Escola. Caderno de formação: formação de professores didática dos conteúdos. Universidade Estadual Paulista, São Paulo, v. 6; 176 p.; 2012.

FERRAZ, C. R. A.; ARAÚJO, M. V.; CARREIRO L. R. R. Inclusão de crianças com Síndrome de Down e paralisia cerebral no ensino fundamental I: comparação dos relatos de mães e professores. Revista Brasileira de Educação Especial, Marília, v.16, n.3, p.397-414, Set.-Dez, 2010.

FORTES, M. O.; AZEVEDO, M. R.; KREMER, M. M. HALLAL, P. C. A Educação Física escolar na cidade de Pelotas, RS: contexto das aulas e conteúdos Rev. educ. fis. UEM, Maringá, vol.23, n.1, Jan./Mar., 2012.

FIORINI, M. L. S.; MANZINI, E. J. Inclusão de alunos com deficiência na aula de educação física: identificando dificuldades, ações e conteúdos para prover a formação do professor. Revista Brasileira de Educação Especial, Marília, v.20, n.3, p.387-404, 2014.

FIORINI, M. L. S.; MANZINI, E. J. Dificuldades e Sucessos de Professores de Educação Física em Relação à Inclusão Escolar. Revista Brasileira de Educação Especial, Marília, v. 22, n.1, p. 49-64, Jan.-Mar., 2016.

GORGATTI, M. G.; ROSE JÚNIOR, D. Percepções dos Professores Quanto à Inclusão de Alunos com Deficiência em Aulas de Educação Física. Revista Movimento, Porto Alegre, v. 15, n. 02, p. 119-140, abril/junho de 2009.

JUNG, L. G.; MARQUES, A. C.; KALINOSKI, A. X.; XAVIER, G. B. Cotidiano da prática de atividade física de crianças e jovens com deficiências da Rede Municipal de Pelotas - RS. Revista Movimento, Porto Alegre, v. 19, n. 02, p. 207-226, abr/jun, 2013.

JUNG, L. G.; KALINOSKI, A. X.; MARQUES, A. C. Barreiras e facilitadores para a atividade física em pessoas com déficit intelectual. Rev Bras Ativ Fís Saúde. 22(4):362-372; 2017.

LEONARDO, N. S. T.; BRAY, C. T.; ROSSATO, S. P. M. Inclusão Escolar: Um Estudo Acerca da Implantação da Proposta em Escolas de Ensino Básico. Revista Brasileira de Educação Especial, Marília, v.15, n.2, p. 289-306, mai/ago, 2009.

LUIZ, F. M. R.; NASCIMENTO, L. C. Inclusão escolar de crianças com síndrome de Down: experiências contadas pelas famílias. Revista Brasileira de

Educação Especial, Marília, v.18, n.1, p.127-140, 2012.

LORENZ, S. Making inclusion work for children with Down syndrome. Down Syndrome News and Update, v.1, n.4, p.175-180, 1999. 
MANTOAN, M. T. E. O direito de ser, sendo diferente, na escola. Revista CEJ, Brasília, n. 26, p. 36-44, 2004.

MARQUES, A.C. O perfil do estilo de vida de pessoas com Síndrome de Down e normas para avaliação da aptidão física. Tese de Doutorado. Programa de Pós-Graduação em Ciências do Movimento Humano, Universidade Federal do Rio Grande do Sul, Porto Alegre, 2008.

NACIF, M. F. P.; FIGUEIREDO, D. H.; NEVES, C. M.; FIGUEIREDO, D. H.; PEDRETTI, A.; PEDRETTI, A.; FERREIRA, M. E. C. Educação Física Escolar: Percepções do Aluno com Deficiência. Revista Brasileira de Educação Especial, Marília, v. 22, n. 1, p. 111-124, Jan.-Mar, 2016.

NAHAS, M. V.; BARROS, M. V. G.; ROSA, J. V. Estilo de vida de pessoas com síndrome de down em Santa Catarina. Revista Brasileira de Atividade Física e Saúde, 4(1), 15-18. 1999.

OMOTE, S. Aparência e competência em Educação Especial. Temas em Educação Especial. São Carlos: UFSCar, v.1, p.11-26, 1990.

ORNELAS, M. A.; SOUZA, C. A CONTRIBUIÇÃO DO PROFISSIONAL DE EDUCAÇÃO FÍSICA NA ESTIMULAÇÃO ESSENCIAL EM CRIANÇAS COM SÍNDROME DE DOWN. Revista da Educação Física/UEM. Maringá, v. 12, n. 1, p. 77-88, 1. sem. 2001.

PADILHA, L. O. EDUCAÇÃO FÍSICA E ESTUDANTES COM DEFICIÊNCIA: OS DESAFIOS DA INCLUSÃO. 87f. Monografia (Graduação). Departamento de Educação Física. Universidade Federal de Santa Catarina, 2017.

PUESCHEL, S. M. Síndrome de Down: guia para pais e educadores. $2^{a}$ Edição, Campinas: Papirus, 1995.

PUESCHEL, S. M. Síndrome de Down: Guia para pais e educadores. $12^{a}$ Edição. Trad. Lúcia Helena Reily. Campinas: Papirus, 2007.

RECHINELI, A.; PORTO, E. T. R.; MOREIRA, W. W. CORPOS DEFICIENTES, EFICIENTES E DIFERENTES: UMA VISÃO A PARTIR DA EDUCAÇÃO FÍSICA. Revista Brasileira de Educação Especial, Marília, v.14, n.2, p.293-310, Mai.-Ago. 2008.

RODRIGUES, D. A educação física perante a educação inclusiva: reflexões conceptuais e metodológicas. Boletim da Sociedade Portuguesa de Educação Física, n. 24/25, p. 73-81, s/d.

SCHWARTZMAN, J. S. et al. Síndrome de Down. $2^{a}$ edição. São Paulo: Memnon: Mackenzie, 2003.

SEABRA, L. Inclusão: Considerações Sobre as Pessoas com Necessidades Especiais na Escola. Caderno de formação: formação de professores didática dos conteúdos. Universidade Estadual Paulista, São Paulo, v. 6; 176 p.; 2012. 
SHERMAN, S.L. et al. Epidemiology of Down Syndrome. Mental Retardation and Developmental Disabilities Research Reviews, v.13, p.221-227, 2007.

SILVA, M. L. P. Estimulação essencial. Por quê? Integração, Brasília, DF, v. 9, n. 16, p. 22, 1996.

SILVA, F. C. M. A percepção dos professores de Educação Física quanto à sua Qualificação para trabalharem com alunos Deficientes na Rede Municipal de Pelotas/RS. 44f. Monografia de Especialização. Curso de Especialização em Educação Física Escolar. Universidade Federal de Pelotas, 2003.

SMEHA, L. N.; OLIVEIRA, V. L. Inclusão escolar: a perspectiva das mães de alunos com Síndrome de Down. Revista Educação Especial, Santa Maria, v. 27, n. 49, p. 403-416, maio/ago, 2014.

SOUZA JÚNIOR, O. M. DARIDO, S. C. DISPENSA DAS AULAS DE EDUCAÇÃO FÍSICA: APONTANDO CAMINHOS PARA MINIMIZAR OS EFEITOS DA ARCAICA LEGISLAÇÃO. Revista Pensar a Prática, v. 12, n. 2, 2009.

TAVARES, L. M. F. L.; SANTOS, L. M. M.; FREITAS, M. N. C. A Educação Inclusiva: um estudo sobre a formação docente. Rev. Bras. Ed. Esp., Marília, v. 22, n. 4, p. 527-542, Out.-Dez., 2016.

TEIXEIRA, F. C.; KUBO, O. M. Características das interações entre alunos com Síndrome de Down e seus colegas de turma no sistema regular de ensino.

Revista Brasileira de Educação Especial, Marília, v. 14, n. 1, p. 75-92, Jan.-Abri. 2008.

TENÓRIO, J. G.; SILVA, C. L. O DESINTERESSE DOS ESTUDANTES PELAS AULAS DE EDUCAÇÃO FÍSICA EM UMA ESCOLA DE ENSINO PÚBLICO DO ESTADO DE MATO GROSSO. SALUSVITA, BaurU: v. 34, n. 1, p. 27-44, 2015.

TRIVIÑOS, A. N. S. Introdução à pesquisa em ciências sociais: a pesquisa qualitativa em educação. São Paulo: Atlas, 1987.

YIN, R. Estudo de Caso. Planejamento e Métodos. Porto Alegre: Bookman, 2001.

Recebido em: 28 de setembro de 2018

Arpovado em: 03 de julho de 2019 